\title{
Assessment on awareness towards preventive measures of COVID-19 in Sheka, Southwestern Ethiopia: Community based cross-sectional Study
}

Assaye Belay Gelaw ( $\square$ abstat23@gmail.com )

Mizan-Tepi University https://orcid.org/0000-0001-7315-9141

Solomon Abebaw Andargie

Mizan-Tepi University

\section{Research}

Keywords: Awareness, Prevention, COVID-19, Pandemic, Knowledge

Posted Date: April 26th, 2021

DOI: https://doi.org/10.21203/rs.3.rs-434491/v1

License: (c) (1) This work is licensed under a Creative Commons Attribution 4.0 International License.

Read Full License 
Assessment on awareness towards preventive measures of COVID-19 in Sheka, Southwestern Ethiopia: Community based cross-sectional Study

Assaye Belay Gelaw ${ }^{1}$, Solomon Abebaw Andargie ${ }^{1}$

${ }^{1}$ Department of Statistics, Mizan-Tepi University, Ethiopia

ABG:abstat23@gmail.com

SAA:solabew@gmail.com

Corresponding Author, abstat23@gmail.com

\begin{abstract}
Background: The coronavirus disease 2019 (COVID-19) is caused by severe acute respiratory syndrome coronavirus 2 (SARS-CoV-2), and it is the most important of public health problem worldwide. A critical element in tackling the COVID-19 crisis is personal behavioral change; however, there is a paucity of evidence about peoples' awareness towards COVID-19 pandemic. Hence, the aim of this was to assess the community's awareness status towards COVID-19 in Sheka, Southwestern Ethiopia.
\end{abstract}

Methods: Community-based cross-sectional study was conducted $10^{\text {th }}$ to $21^{\text {th }}$ April 2020. Four hundred-nineteen individuals participated during the study. Both univariable and multivariable logistic regression analyses were used to identify significant factors of awareness status, and variables with $\mathrm{p}$-value $<0.05$ indicated it significantly influences the awareness status of the individuals towards COVID-19.

Results: According to the study's results, nearly half (49.4\%) of the participants had awareness about COVID-19 pandemic. Factors such being female equal (AOR: 0.476, 95\%CI: 0.293, 0.772),education being secondary and above(AOR:2.178,95\%CI:1.323,3.586), and prevention methods being fully used (AOR,8.127,95\%CI: 1.273, 51.871)were significantly influencing the awareness status of the community towards COVID-19 pandemic than their counterparts.

Conclusion: The study showed that there is a low awareness status among people towards COVID-19.Hence, programs to improve awareness towards COVID-19 pandemic is essential to prevent and control the pandemic.

Keywords: Awareness, Prevention, COVID-19, Pandemic, Knowledge 


\section{Introduction}

Coronavirus is among the diverse families of viruses and a source of illness of the disease ranging from the common cold to more several diseases such as middle respiratory syndrome $(1,2)$.COVID-19 case was first reported on 31 month of December 2019 in Wuhan city of China. Since then, it has been rapidly spreading as infectious disease, which has now developed to the global pandemic(3). The pandemic is affecting all major world economies; predicting to cause huge global economic crisis in 2020(1). Currently, the virus is spreading to the entire world and can infect people of all age groups. Older people and those with pre-existing medical history problems are more vulnerable to becoming severely ill with the virus (4-7). COVID-19 can be transmitted through droplets and fomites during close unprotected contact between an infected and healthy person. The airborne spread has not been reported for COVID-19, and there is no big driver of transmission based on available evidence (8).

Novel coronavirus case was first happened in Ethiopia on the $13^{\text {th }}$,March 2020 and preventive measures against COVID-19 is continuing in all parts of the country(9).

COVID-19 pandemic impact on declines in tourism, business travel, spillovers of weak demand to other sectors, economies through trade and production linkages. Similarly, supply-side disruptions to production and trade and effects on health such as increased disease and mortality as well as shifts in health care spending are the major impacts of COVID-19 pandemic (10-12). The COVID-19 is affecting educational systems worldwide, and it is leading to the widespread closures of schools and universities. The virus affected over 1.5 billion students worldwide, accounting for $87 \%$ of enrolled learners $(13,14)$.

The related study done in Ethiopia, there is still a big issue in preventing and control the pandemic because most of the community assumed that the disease cease, and the general public has little understanding or awareness about the disease(15). Communities must save themselves and others from COVID-19 by considering the following important habits such as regular hand washing, use sanitizers, avoid touching their faces ,practice covering their mouths, noises at any time while coughing and sneezing, keep physical distance and isolate themselves if any feeling of illness and the like(16-19). Ethiopia is now sharing a major proportion of the global burden of infectious diseases, while the patterns of COVID-19 are still at an earlier stage of the epidemiology curve. The Ethiopian government exerted tremendous efforts to curb the disease (20). Globally, COVAX vaccine is producing and it has targeted immunization that covers of at least $20 \%$ of the population in each participating country by the end of 2021 , and has contracted for 2 billion doses of COVID-19 vaccines; however, it is neither inclusive nor adequately planned. The timely supply of vaccines to COVAX is questionable in low-income countries because high-income countries (HICs) step to the front of the queue for limited supplies of COVID-19 vaccines(21).

Awareness is very important for establishing prevention beliefs and promoting positive behaviors to be effective to prevent the spread of the pandemic (22). Myths and false assurances were the most prevalent perceived inhibitors of the spread of COVID-19 compared to the perception that engagement in precautionary measures protect from exposure to and spread of the virus(23). Currently in almost all of the scientific journals, COVID- 19 related 
scientific investigations ranging from the trial of effective therapeutics and vaccines to short and long term impacts of COVID-19 on the different sectors are the priority issues(24).

Currently, there is (COVAX) vaccine or treatment that is officially giving to individuals for both developing and developed countries to prevent COVID-19. Though messages related to COVID-19 transferred from health professionals and other concerned bodies frequently, still the utilization of preventive measures is low in our observation. A critical element in tackling the COVID-19 crisis is public behavior change. Behavior change requires

public understanding, acceptance, and implementation of the recommended prevention methods. There is a paucity of evidence showing the status of individual awareness towards COVID-19 in Ethiopia. Thus, the aim of this study was to assess the awareness status of people towards COVID-19 in Sheka, Southwestern Ethiopia.

\section{Methodology}

\section{Study area and design}

The current study was conducted in Sheka Southwestern Ethiopia, and Tepi city administration. The zonal city is located $951 \mathrm{Km}$ to North West of Awassa, the capital of SNNPR and $676 \mathrm{~km}$ to Southwest of Addis Ababa. Sheka is bordered on the south by Benchi-Sheko, on the west by the Gambela Region, on the north by the Oromiya Region, and on the east by Kaffa Zone. Administratively, the Sheka Zone structured into three provinces and two city administrations. A community-based cross-sectional study was conducted in between $10^{\text {th }}$ to $21^{\text {th }}$ of April 2020 . The study populations were all those who are living in Sheka Zone, Southwestern Ethiopia.

\section{Sampling Procedure}

The study population was both female and male adults whose age ( $>=18$ years) who were selected by chance walking along in the study sites. The sample size was calculated in a single population proportion formula. Hence, simple random sampling technique was used, because the population who lived in the study area is homogenous and has equal chance of being selected. In sample size calculation, maximum proportion (50\%) was considered. It is because there was no previous study done in the study area about awareness status of the community about COVID19.

Henceforth, confidence level, margin of error, and expected maximum proportion were considered for calculating the sample size (25).The required sample size was computed as $z_{\alpha / 2}$ is at $95 \%$ confidence level for normal distribution, which is $1.96, d$ is a margin of error $(5 \%)$,and $10 \%$ none response rate was considered. Thus, considering $p=0.5$ or $50 \%$ (a maximum proportion for the awareness of individuals about COVID-19 pandemic because of no previous study was done), the sample size for this study becomes:

$$
\begin{aligned}
n=\frac{\left(z_{\alpha / 2}\right)^{2} p *(1-p)}{(d)^{2}} & =\frac{(1.96)^{2} * 0.5 *(1-0.5)}{(0.05)^{2}} \\
& =384.5, \text { and ten percent of the non reponse rate }(38.5) \text { were added }(384.5 \\
& +38.45 \sim 424) .
\end{aligned}
$$




\section{Data collection tools and procedure}

The data were collected using structured administered questionnaire with interview that was prepared based on the study objectives. The data collection tool was initially prepared in English version were followed by translation to local Amharic language. Hence, the consistency and appropriate meaning between two versions was maintained through back translation of the questionnaire to the original version. The source of questionnaires was literatures that are related to the current study. Research committee and health officers approved the validity of the questionnaire. Six health extension workers enrolled for twelve days (10 to21 April 2020) for data collection to complete the questionnaire participants. One-day training was given for data collectors by the investigators to control the quality of data.

The researchers supervised the overall activities during data collection period .Hence, the questionnaire was prepared based on the COVID-19 pandemic prevention and control mechanisms that was recommend by both ministry of health of Ethiopia, and Ethiopian government, and also by world health organization recommendation. Consequently, socio-demographic factors, coronavirus prevention and control related factors were measured.

\section{The study variables}

The outcome variable was the awareness status of participants dichotomized as aware and not aware (measured from understanding towards COVID-19 pandemic).

The participants are aware when she or he did know about COVID-19 prevention methods and control mechanism that were recommended by world health organization (WHO), and not aware when the participants have poor understanding in the direction of COVID-19 prevention methods and control mechanism.

The socio-demographic factors such as age, sex, level of education, religion, source of income, prevention method used, knowing symptoms, use of quarantine, treatment, source of information, level of implementing of government and health professionals' declaration perceived by individuals, and pre-existing health condition of participants were measured from structural administered questionnaire.

\section{Data analysis}

Data were analyzed using SPSS software package (version 20). Frequency distribution, percentage, and plots were used to provide sound results(26). The chi-square test was applied to examine the association between factors and the dependent variable. The logistic regression model was used to express the dependent variable or the response variable qualitatively expressed(27).

Binary logistic regression is the form of regression, which is used when the dependent variable is dichotomous, and the independent variables are any type. A binary variable has only two possible values, such as presence or absence of a particular event, in our study to identify whether the participants had awareness towards COVID-19 pandemic not.

Model $: \ln \left(P_{i} / 1-P_{i}\right)=\beta_{0}+\beta_{1} X_{1 i}+\beta_{2} X_{2 i}+\ldots \ldots \beta_{k} X_{k i}$. 
The odds are simply the ratio of the probabilities for the two possible outcomes[28].If $P_{i}$ is the probability that an event will occur, and then $1-P_{i}$ is the probability that an event will not occur. odds $=\frac{p_{i}}{1-p_{i}}$. Let in $2 \times 2$ tables, within row 1 the odds of success are odds $s_{1}=p_{1} / 1-p_{1}$ and within row 2 the odds of success equal odds $s_{2}=$ $p_{2} / 1-p_{2}$. The ratio of the odds from the two rows (odd ratio) is given byodds Ratio $=\theta=\frac{\text { odds } s_{1}}{\text { odds }}=\frac{p_{1}}{1} / 1-p_{1} /$ $p_{2} / 1-p_{2}$

\section{Parameters Estimation}

The maximum likelihood and Wald test were used for parameter estimation methods in fitting logistic regression model.

The maximum likelihood estimates of the parameters could be obtained by maximizing the log-likelihood function from (ii) is given by $p_{i}=\frac{e^{\left(\beta_{0}+\beta_{1} X_{1 i}+\beta_{2} X_{2 i}+\ldots \ldots \ldots \beta_{k} X_{k i}\right)}}{1+e^{\left(\beta_{0}+\beta_{1} X_{1 i}+\beta_{2} X_{2 i}+\ldots \ldots \ldots \beta_{k} X_{k i}\right)}}$ [27]. Since observe values of $Y$ say, $Y_{i}$ 's $(i=1,2 \ldots n)$ are independently distributed as Bernoulli, the maximum likelihood function of $\mathrm{Y}$ is given by:

$$
L(\beta / y)=\prod_{i=1}^{n} p\left(y_{i} / x_{i}^{i}\right)=\prod_{i=1}^{n}\left[\frac{e^{x_{i}^{\prime} \beta_{i}}}{1+e^{x_{i}{ }^{i} \beta_{i}}}\right]^{y_{i}}=\left[\frac{1}{1+e^{x_{i}^{\prime} \beta_{i}}}\right]^{\left(1-y_{i}\right)}
$$

Wald $\chi^{2}$ statistics is used to test the significance of individual coefficients in the model and are calculated as follows: Wald $=\left[\frac{\beta}{\operatorname{se}(\beta)}\right]^{2} \sim \chi^{2}$ distribution with one degree of freedom.

\section{Assessments of the fitted model}

The Wald test is the most computing parameter estimation method for logistic regression method. After the model is fitted, the next important step is checking the model adequacy. Therefore, the Hosmer-Lemeshow test was used [29].

\section{Results}

The response rate of the respondents was $98.8 \%$ ( 419/424). The socio-demographic factors of the study participants were illustrated in Table 1. Four hundred-nineteen respondents participated in the survey and among the respondents, 207 (49.4\%) had awareness, and 212 (50.6\%) did not have an awareness towards COVID-19 pandemic, which was an almost equal proportion of awareness. Of the total respondents, males accounting, 97(46.9\%), and females accounting, 110 (53.1\%) had awareness towards COVID-19 pandemic.

Table 1.Socio-demographic characteristics of the study participants $(n=419)$

\begin{tabular}{llllll}
\hline & & \multicolumn{2}{c}{ Awareness status (\%) } & Chi-square & \\
Variables & Categories & Yes & No & df & P-value \\
\hline Gender & Male & $97(46.9)$ & $68(32.1)$ & 1 & 0.002 \\
& Female & $110(53.1)$ & $144(67.9)$ & & \\
Age & Less than 20 & $15(7.2)$ & $5(2.4)$ & 5 & 0.009
\end{tabular}




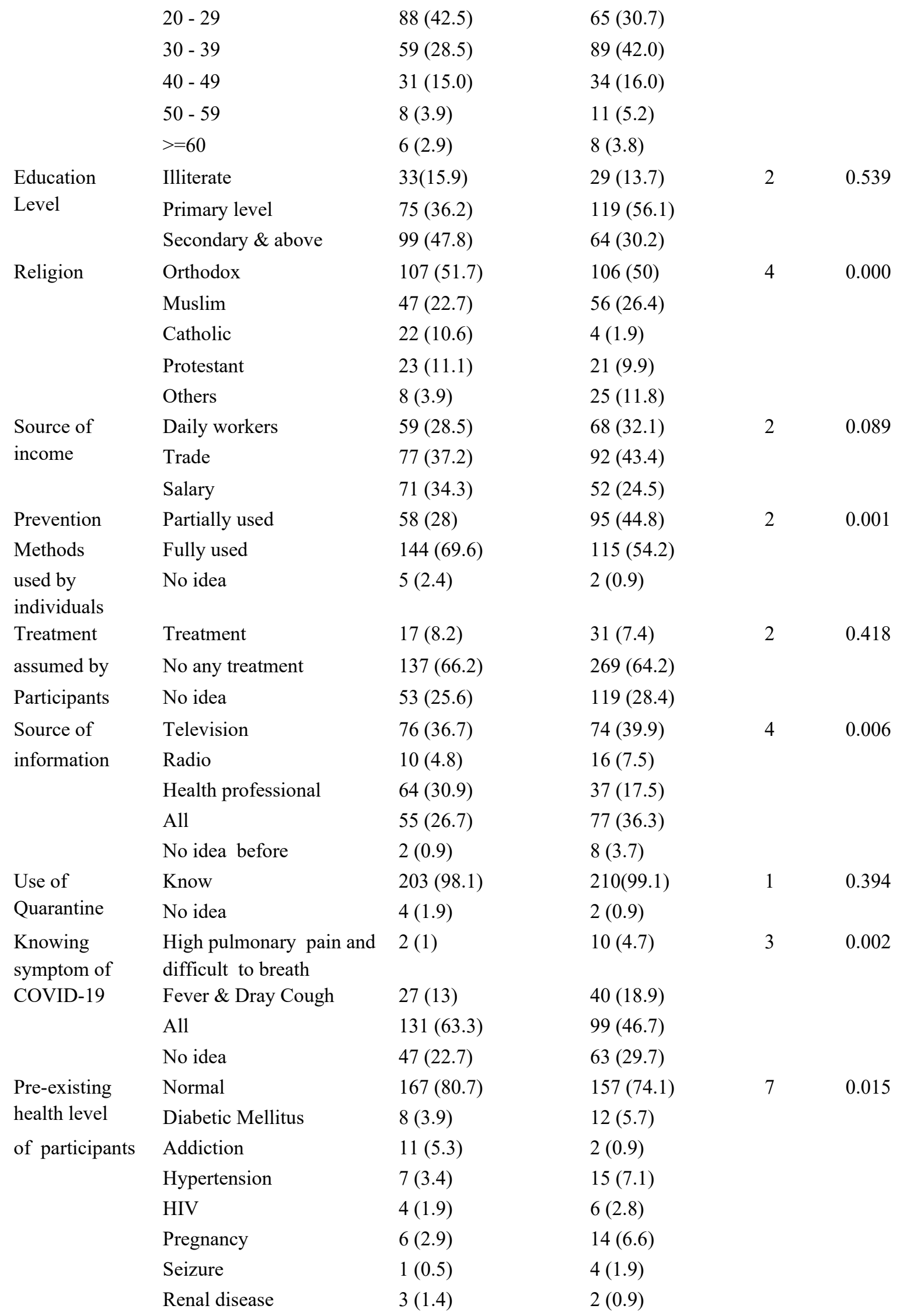




$\begin{array}{llllll}\text { Level of } & \text { Fair } & 98(47.3) & 123(58.0) & 4 & 0.004 \\ \text { implementation } & \text { Medium } & 68(32.9) & 74(34.9) & & \\ \text { perceived } & \text { High } & 22(10.6) & 8(3.8) & \\ & \text { Very high } & 13(6.3) & 3(1.4) \\ & \text { No idea } & 6(2.9) & 4(1.9) & \end{array}$

The educational level of respondents increased proportion of awareness of the COVID-19 pandemic. The percentage of understanding is (15.9\%) for non-educated participants, (36.2\%) for primary educated participants and (47.8\%) for respondents whose education level is secondary and above had an awareness of COVID-19.

Concerning the source of information,76 (36.7\%), 10 (4.8\%), 64(30.9\%), 55(26.7\%) and 2(0.9\%) of respondents obtained information about COVID-19 from Television, Radio, Health professionals, and no source information respectively had an awareness of COVID-19 pandemic.

Table 1 also illustrated prevention methods recommended by the world health organization (WHO) that were used by the respondents. Thus, 58 (28\%), $144(69.6 \%)$ and 5(2.4\%) of respondents used prevention methods partially, fully used or apply all WHO recommended prevention methods and no idea for prevention or they did not apply WHO recommended prevention methods respectively had an awareness of COVID-19 diseases.

$210(99.1 \%)$ of participants who were informed about the use of quarantine were aware of the preventive measures of COVID-19 while,2 (0.9\%) of those who had no idea about the quarantine were not aware.

Table 1 also shows the pre-existing health level of respondents; the pre-existing health level of respondents were 324 (77.3\%), 20 (4.8\%), 13(3.1\%), 22(5.3\%), 10(2.4\%), 20 (4.8\%) and 5 (1.2\%) respectively are normal, diabetic mellitus, addiction, hypertension, HIV+, pregnancy, seizure, and renal disease. The participants' awareness status differed significantly across/among all socio-demographic except for, the source of income, treatment, use of quarantine or isolation, and educational level. 


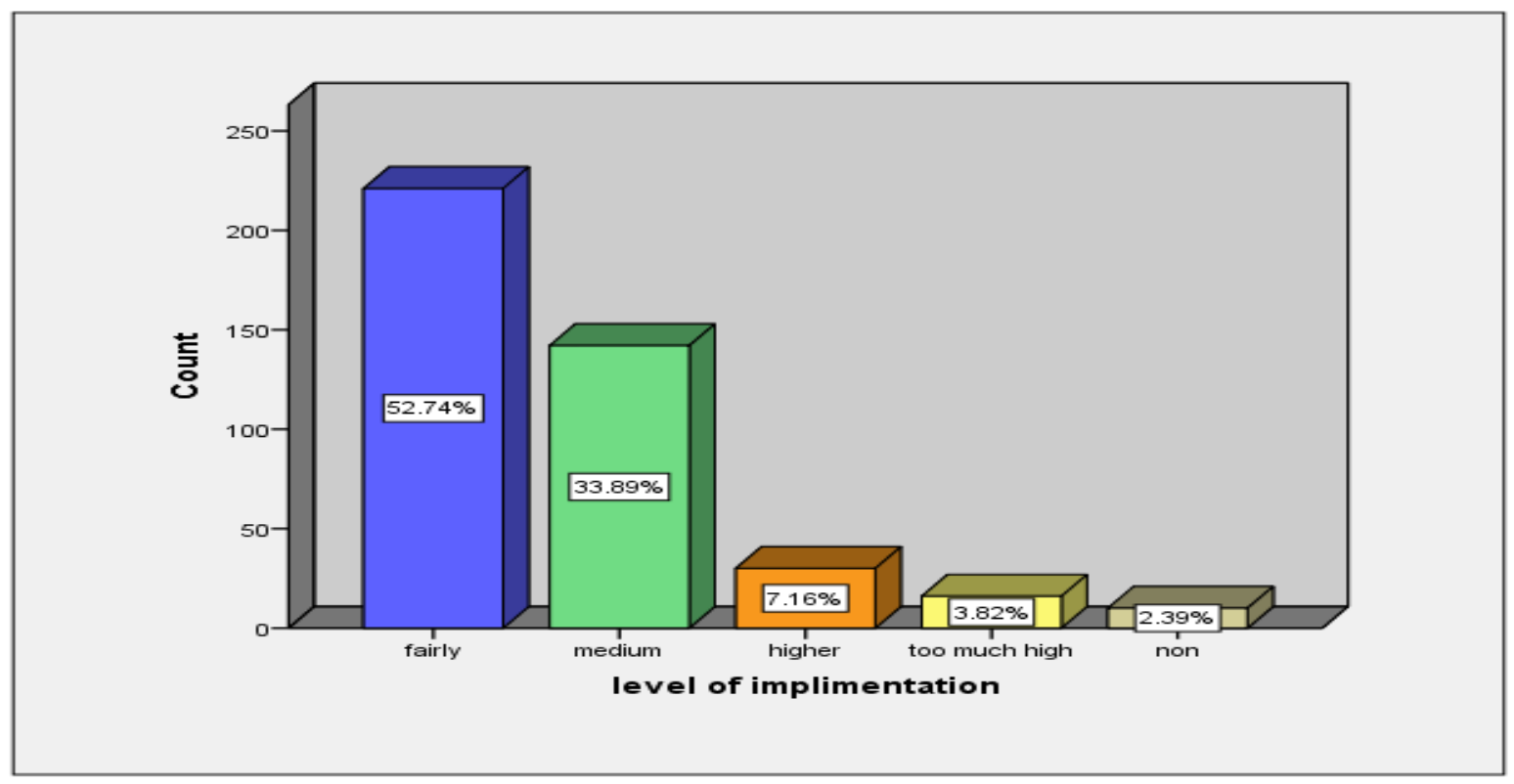

Figure 1: Level of implementation the government declaration regarding COVID-19 by individuals

Figure 1 show that 52.74 percent of respondents fairly implemented, 33.09 percent applied in the medium, 7.16 percent applied highly implemented, 2.39 percent implemented too high, and 0.48 percent not implemented for government declaration towards COVID-19 pandemic.

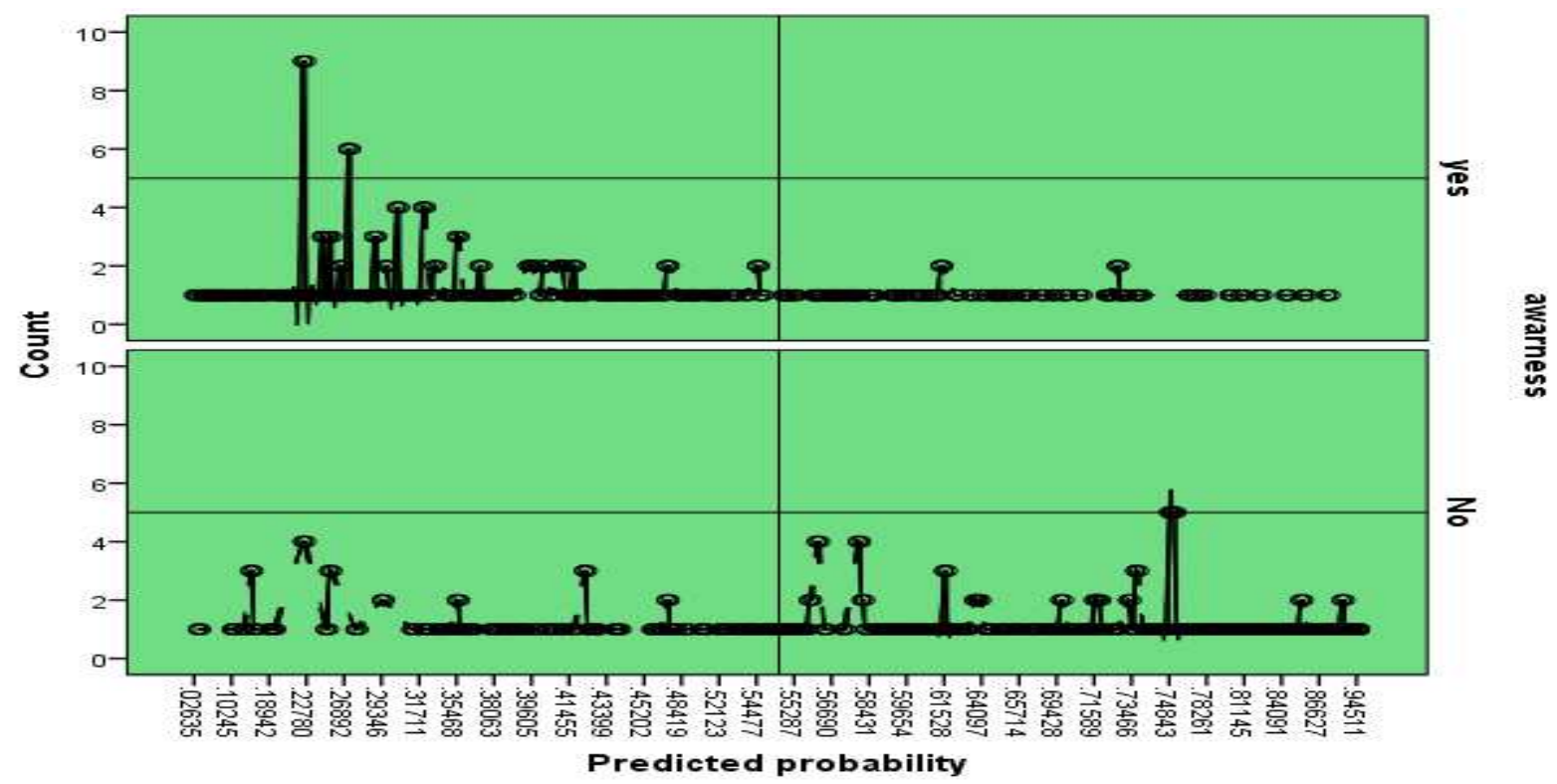

Figure 2: Predicted probability of individual towards COVID-19

Figure 2 showed that the probability of the individual's awareness towards COVID-19 is decreasing, whereas the chance those individuals will not be aware of COVID-19 increases. It implies an awareness creation strategy to maximize the individual's awareness of COVID-19 pandemic. 
Table 2: Hosmer and Lemeshow Test of good ness of fit

\begin{tabular}{lcc}
\hline Chi-square & df & Sig. \\
14.911 & 8 & 0.061 \\
\hline
\end{tabular}

The $\chi^{2}$ statistic with 8 degrees of freedom is 14.911 , and the p-value is 0.06 . Thus, the model well fitted the data (Table 2).

Table 3: The Observed and the Predicted Frequencies on Awareness of Respondents towards COVID-19 by Logistic Regression with the Cutoff of 0.50

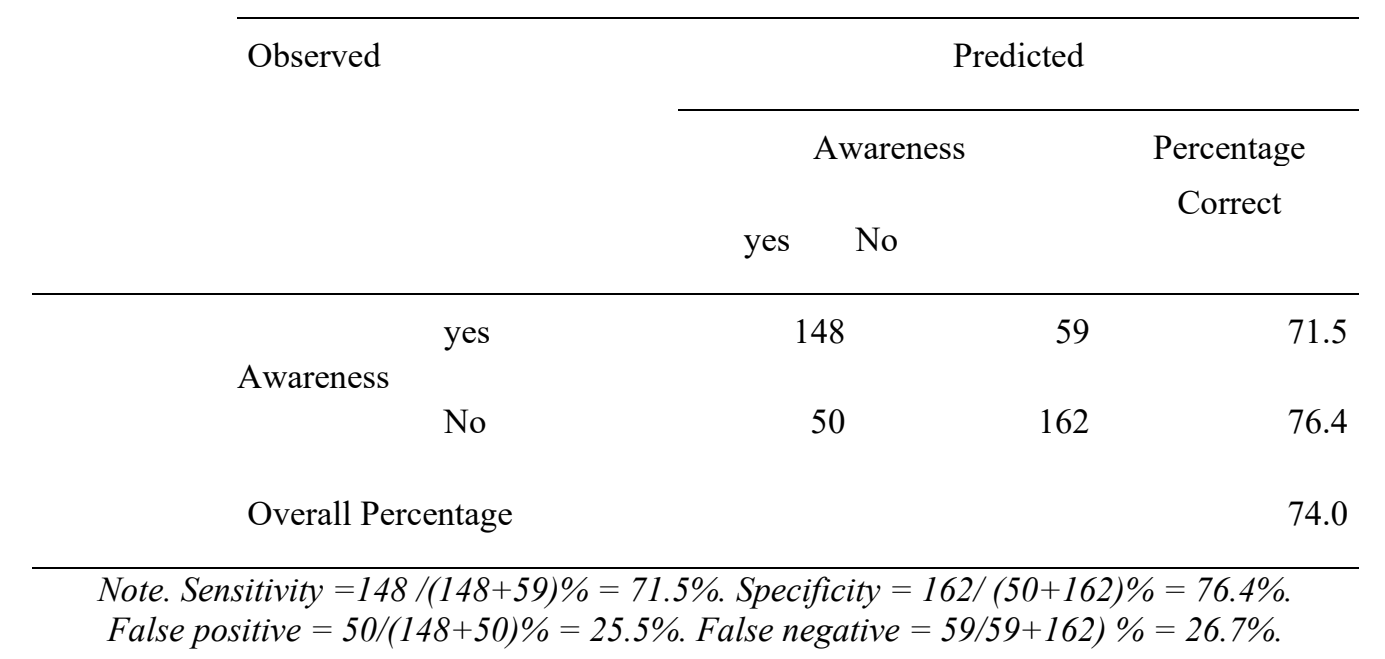

A classification table used to distinguish accurately predicted value of awareness of respondents towards COVID-19 (Table 3). The table is indicating the validity of predicted probabilities (Table 3). The first two rows in Table 3 stands for the two possible outcomes, and the two columns under the heading predicted are for high and low probabilities.

The observation also held in the sensitivity (71. 5\%) as compared to that of specificity $(76.4 \%)$. Sensitivity measured the correct proportion of classified events (the awareness of individuals towards COVID-19). Specificity measures the true proportion of classified non-events (those not suggested for awareness of individuals towards COVID-19). Both false positive and false negative rates are a little more than $25 \%$. The false positive and falsenegative rate respectively measure the proportion of observing misclassified as events and miss classified as nonevents. Thus, the overall correction prediction was $74 \%$ on the progress over the chance level to aware of the COVID-19 pandemic.

Table 4: Parameter estimates of binary logistic regression using forward stepwise variable selection Method.

\begin{tabular}{|c|c|c|c|c|c|c|c|c|c|}
\hline \multirow[t]{2}{*}{ Variables } & \multirow[t]{2}{*}{ Categories } & \multirow[t]{2}{*}{$\beta$} & \multirow[t]{2}{*}{ S.er. } & \multirow[t]{2}{*}{ Wald } & \multirow[t]{2}{*}{$\mathrm{df}$} & \multirow[t]{2}{*}{ P-value } & \multirow[t]{2}{*}{ AOR } & \multicolumn{2}{|c|}{ 95\% C.I. for $\operatorname{EXP}(B)$} \\
\hline & & & & & & & & Lower & Upper \\
\hline Sex & Male (ref) & & & & & & & & \\
\hline
\end{tabular}




\begin{tabular}{llllllllll} 
& Female & -0.743 & 0.247 & 9.061 & 1 & 0.003 & 0.476 & 0.293 & 0.772 \\
education & Illiterate(ref) & & & & & & & & \\
& Elementary & -0.349 & 0.361 & .933 & 1 & 0.334 & 0.706 & 0.348 & 1.431 \\
& Secondary + & 0.779 & 0.254 & 9.374 & 1 & 0.002 & 2.178 & 1.323 & 3.586 \\
Religion & Orthodox (ref) & & & 15.395 & 4 & 0.004 & & & \\
& Muslim & -1.238 & 0.493 & 6.300 & 1 & 0.012 & 0.290 & 0.110 & 0.762 \\
& Catholic & -1.048 & 0.522 & 4.026 & 1 & 0.045 & 0.351 & 0.126 & 0.976 \\
& Protestant & -2.879 & 0.749 & 14.771 & 1 & 0.000 & 0.056 & 0.013 & 0.244 \\
& Others & -1.327 & 0.576 & 5.301 & 1 & 0.021 & 0.265 & 0.086 & 0.821 \\
Symptoms & Pulmonary and difficult & & & & & & & & \\
& to breath (ref) & & & & & & & & \\
& fev,dry cough & 1.718 & 0.979 & 3.076 & 1 & 0.079 & 5.572 & 0.817 & 37.991 \\
& All & 0.265 & 0.401 & .436 & 1 & 0.509 & 1.303 & 0.594 & 2.857 \\
$\begin{array}{l}\text { Prevention } \\
\text { methods } \\
\text { used }\end{array}$ & Portially(ref) & -0.541 & 0.285 & 3.593 & 1 & 0.058 & 0.582 & 0.333 & 1.019 \\
& Fully used & & & & & & & & \\
& None of used & 1.095 & 0.946 & 4.908 & 1 & 0.027 & 8.127 & 1.273 & 51.871 \\
\hline
\end{tabular}

$*=\mathrm{P}<0.05 *$

The results from multivariable analysis revealed that sex being female, religion being muslim, catholic, protestant and others, education level being secondary and above, prevention methods being fully used were significant factors for awareness status of the community towards COVID-19(Table 4).

The odds ratio of education being (secondary and above) ( AOR:2.178,95\% CI: 1.323, 3.586) (adjusted other variables). The respondents whose education level being secondary and above were 2.178 times more likely to aware of COVID-19 than respondents whose education level is illiterate(Table 4). The odds ratio of religion being (Muslim, catholic, protestant and others) are respectively [AOR: 0.290, 0.351, 0.056, 0.265; 95\% CI: $(0.110,0.762)$; $(0.126,0.976) ;(0.013,0.244) ;(0.086,0.821]$ (adjusted others variables). The respondents whose religion being muslim, catholic, protestant, and others respectively were $0.290,0.351,0.056$ and 0.265 times less likely to aware of COVID-19 pandemic than those respondents whose religion was orthodox (Table 4).

The odd ratio of prevention method being fully used (AOR: 8.127; 95\%CI: 1.273, 51.871) (other variables are adjusted) was 8.127 times more likely to aware about COVID-19 pandemic than those respondents who partially used (at most three prevention method have used).

The odd ratio of sex being female (AOR: $0.473 ; 95 \% \mathrm{CI}: 0.293,0.772$ ) (other variables are adjusted) was 0.473 times less likely to aware about COVID-19 than the respondents who were male. 


\section{Discussion}

Now days, the COVID-19 pandemic is accelerating worldwide. The Ethiopian government is taking many measurements to tackle the impact of COVID-19 on any business sector and the wellbeing of individuals. It is, therefore, mandatory to explore the effects of COVID-19 in Ethiopia and to set out immediate priorities and longerterm strategies for appropriate interventions. Culturally, in Ethiopia, it is hard to apply all COVID-19 prevention strategies since individuals are highly sociable, culturally indispensable among each other, and the marketing system is traditional.

The COVID-19 is a current language spoken by almost all media all over the world. However, society is still not aware of the risk of COVID-19 pandemic. The study showed that $50.6 \%$ of participants did not have awareness about the COVID-19 pandemic. The overall correction prediction value was $74 \%$. It is an improvement over the chance to be aware of the COVID-19 pandemic, and $26 \%$ chances did not get being aware of COVID-19. The current study is consistent with the study done in the awareness of the individual towards COVID-19 disease(16).

Hence, much effort is needed to be done towards awareness for the individual about COVID-19 by assessing sociodemographic factors and the individual's perception towards COVD-19 pandemic management. Quarantine is one mechanism to control the coronavirus pandemic. The study showed that about ninety-eight percent of the societies had awareness about quarantine. The current study is consistent with the study done in Middle East Respiratory Syndrome Coronavirus epidemic impact on healthcare workers' risk perceptions, work and personal lives(28) and also consistent with the study conducted in Vietnam where $97.9 \%$ of the participants agree to quarantine(29).

According to the world health organization (WHO) advice, the individual expected to be high risk by COVID-19 pandemic if their current health level is pregnancy, seizure, hypertension, diabetic Miletus, addiction, HIV, chronic pulmonary and chronic renal disease. The study showed that people with diabetic Miletus, hypertension, HIV, and renal disease patients considered to be at high risk of suspected to COVID-19 infection.

Thus, special attention should be given to the high susceptive society in the town administration by creating awareness about the COVID-19 pandemic (table 1). According to this study, $2.39 \%$ of participants never implemented the government, and health professions advice how to prevent coronavirus pandemic prevention strategies (figure 1).

Currently, there is no vaccine or treatment to coronavirus pandemic. However, still, there is a myth that there is vaccine to prevent the disease. In the study, $8.2 \%$ of individuals assumed that there is a vaccine, and these results showed that it is risky to manage the pandemic. The level of implementation of government and health professional declaration regarding COVID-19 pandemic overall prevention strategies are questionable since some individuals were not still implementing the government declaration.

The awareness of some individuals depends on religious aspects. Some religions may preach that the disease becomes from God and so that it is so hard to stop by government declaration and health professionals. The model may tell us some religions are less aware (religion concern) than other religions even if we cannot recommend which religion is better. As it is known, the Ethiopian religious association agreed to announce declaration for one 
month to pray to tackle the hidden challenge of the pandemic, which is an unseen enemy causing multitude of socioeconomic crisis all over regardless of all aspects in the world.

The study found that mass media and public health care workers were the most important sources of information in Sheka Zone, Tepi Town administration for individual's awareness towards COVID-19 pandemic. This finding is similar to Myanmar adults study because it used the familiar sources which are social media and mass media(30). Also the study conducted in Hong Kong in which their common sources were social platform and mass media but different with health care workers study in which their primary sources were not only social media but also official government websites $(31,32)$ and in Pakistan healthcare professionals study reveal the same result with the current study (33).

The multivariable binary logistic regression was used to identify the factors influencing society's awareness of COVID-19. The results showed that sex, educational level, and preventive strategies are significant factors in the understanding of individuals. These findings were similar to the study conducted in Myanmar adults on awareness, perceived risk, and protective behaviors to COVID-19 and in Saudi Arabia(30,34).

\section{Limitation of study}

This study is limited because of cross-sectional design, which cannot determine the cause and effect relationship .In addition, the study was done as early as the pandemic expanded in Ethiopia, and for this many literatures were not reviewed in first development of the study,

\section{Generalizability of the results}

The study results generalized on the whole population because of the study used principle probability sampling technique, and appropriate statistical procedures. Thus, more than ninety-eight percent of participants actively participated during the survey.

\section{Conclusions}

The finding highlights the awareness status of participants towards COVID-19 in Sheka, South Nation Nationalities' Peoples of Region, Tepi town administration, Southwestern Ethiopia, and individuals presently practicing concerning COVID-19 pandemic. The study assessed individuals' awareness and experience in the direction of COVID-19 pandemic. According to our finding, the main factors for being aware are sex being female, education level being secondary and above level, religion being muslim, protestant and others, knowing symptoms of COVID19 and prevention strategies. The study found that below half of the respondents (49.4\%) agreed on the essential role of individuals in the prevention of COVID-19 pandemic. In addition, the finding confirmed that more than half $(50.6 \%)$ of the individuals had no awareness and poor protecting experience to prevent COVID-19 pandemic. The study found 54.18 percent of the individuals fairly implemented and 0.48 percent of the individuals did not put into effect the government declaration strategies to stop COVID-19 pandemic. The study was also capable of highlighting gaps in the precise element of perception and preventive experience that should center in future attention and instructional campaigns. 
Further study should be done and explored by including other factors that are not addressed in this study.

\section{Abbreviations}

CDC: Centers for Disease Control and Prevention

COVID-19: Coronavirus Disease 2019

AOR: Adjusted Odd Ratio

WHO: World Health Organization

SNPPR: South Nation Nationalities and Peoples of Region

\section{Declarations}

\section{Ethics approval and consent to participate}

Written permission was obtained from Mizan-TepiUniversity, with reference number MTU/19/86//09/2020 to Tepi Town Public Health Office and then they approved it.

The Approval Committees were:

i. Yideg Mamo, Chief Executive of Mizan-Tepi University,e-mail:mamoyideg@gmail.com

ii. Bizuwork Derebew: College of Natural and Computational Science, Dean, e-mail:bizusi@gmail.com

iii. Abatneh Bayu, Head of Public Health, City Administration, and Phone №:+251-917187502

iv. Yetemwork Aragie, Public Health Officer, City Administration, and Phone №:+251-906413734

The participants were told them about the study objectives and the provided information kept confidentially. They were also told them that they have the right to say no the interview even in the at the time of survey if they are inconvenient

\section{Consent for Publish}

Not applicable

\section{Availability of data and materials}

The data will be given upon on request behalf of corresponding author.

\section{Competing interests}

No potential conflict of interest was declared.

\section{Funding}

The fund was sponsored by Mizan-Tepi University for data collection. However, there is no role for data analysis, interpretation and in writing the manuscript.

\section{Authors 'contributions}

Both authors were responsible for the conception, data analysis, interpretation of the results, writing manuscript. Finally, all authors had read and approved the manuscript.

\section{Acknowledgments}

All who directly or indirectly contributed for this study are duly acknowledged.

\section{Authors 'information}


Assaye Belay Gelaw: I was graduated BSc degree in Statistics from Wollega University in 2010. Ministry of higher education in Ethiopia has assigned me in Mizan-Tepi University as assistant instructor I and II. After two years' service of teaching, I have joined to Jimma University to study MSc in Biostatistics and graduated in 2015. Now, I am lecturer of Statistics at Mizan -Tepi University, College of Natural and Computational Science, Department of Statistics.

Solomon Abebaw Andargie: He was graduated BSc degree in Statistics from University of Gondar in 2010. Ministry of higher education in Ethiopia has assigned him in Mizan-Tepi University as assistant instructor I and II. After two years' service of teaching, he has joined to Jimma University to study MSc in Biostatistics and graduated in 2016. Now, he is lecturer of Statistics at Mizan -Tepi University, College of Natural and Computational Science, Department of Statistics.

\section{Reference}

1. Yan J, Zhang M, Liu X, Zhou P, Huang J, Ye K. Public's Knowledge, Attitude and Practice towards COVID-19 in the Normalization Stage of Plague Prevention and Control : A Cross-sectional Survey in China. Sci Publ Gr. 2021;10(December 2019):1-7.

2. Van Der Hoek L, Pyrc K, Jebbink MF, Vermeulen-Oost W, Berkhout RJM, Wolthers KC, et al. Identification of a new human coronavirus. Nat Med. 2004;10(4):368-73.

3. Okello G, Izudi J, Teguzirigwa S, Kakinda A, Van Hal G. Findings of a Cross-Sectional Survey on Knowledge, Attitudes, and Practices about COVID-19 in Uganda: Implications for Public Health Prevention and Control Measures. Biomed Res Int. 2020;2020:8.

4. CDC. What you need to know about COVID-19 Coronavirus Disease. 2020;314937.

5. Adhikari SP, Meng S, Wu Y, Mao Y, Ye R, Wang Q, et al. A literature review of 2019 Novel Coronavirus during the early outbreak period: Epidemiology, causes, clinical manifestation and diagnosis, prevention and control. Infect Dis Poverty. 2020;9(29):1-12.

6. Munster VJ, Koopmans M, van Doremalen N, van Riel D, de Wit E. A novel coronavirus emerging in China - Key questions for impact assessment. N Engl J Med. 2020;382(8):692-4.

7. Pullano G, Pinotti F, Valdano E, Boëlle PY, Poletto C, Colizza V. Novel coronavirus (2019-nCoV) earlystage importation risk to Europe, January 2020. Euro Surveill. 2020;25(4):1-5.

8. Aylward, Bruce (WHO); Liang W (PRC). Report of the WHO-China Joint Mission on Coronavirus Disease 2019 (COVID-19). WHO-China Jt Mission Coronavirus Dis 2019. 2020;2019(February):16-24.

9. Tadesse DL. Ethiopia confirms first coronavirus case. In: Live updates" Aljazeera.com Archived from the original. 2020. 
10. ADB-factsheet. The Economic Impact of the COVID-19 Outbreak on Developing Asia. 2020;9(128).

11. Evans O. Socio-economic impacts of novel coronavirus: The policy solutions. B I Z E C O N S Q U A R T E R L Y. 2020;7(March):3-12.

12. Demertzis M, Sapir A, Tagliapietra S, Wolf GB. An effective economic response to the coronavirus in Europe. 2020;(Policy Contribution 06/2020, Bruegel).

13. Mohamed A, Elhassan E, Mohamed A, Mohammed AA, Edris HA, Mahgoop MA, et al. Knowledge, attitude and practice of the Sudanese people towards COVID-19: An online survey. BMC Public Health. 2020;21(274):1-7.

14. Covid- U, Response E, Sector E. UNESCO COVID-19 Education Response Education Sector issue notes Anticipated impact of COVID-19 on public expenditures on education and implication for UNESCO work. Educ Sect. 2020;(April):1-6.

15. Kassa AM, Mekonen AM, Yesuf KA, Woday Tadesse A, Bogale GG. Knowledge level and factors influencing prevention of COVID-19 pandemic among residents of Dessie and Kombolcha City administrations, North-East Ethiopia: A population-based cross-sectional study. BMJ Open. 2020;10(11):19.

16. Hou Y, Tan Y, Lim WY, Lee V, Wei L, Tan L, et al. Adequacy of public health communications on H7N9 and MERS in Singapore : insights from a community based cross-sectional study. BMC Public Health. 2018;18(436):1-11.

17. Mersha A, Shibiru S, Girma M, Ayele G, Bante A, Kassa M, et al. Perceived barriers to the practice of preventive measures for COVID-19 pandemic among health professionals in public health facilities of the Gamo zone, southern Ethiopia: a phenomenological study. BMC Public Health. 2021;21(1):1-10.

18. Desalegn Z, Deyessa N, Teka B, Shiferaw W, Hailemariam D, Addissie A, et al. COVID-19 and the public response: Knowledge, attitude and practice of the public in mitigating the pandemic in Addis Ababa, Ethiopia. PLoS One [Internet]. 2021;16(1 January):1-16. Available from: http://dx.doi.org/10.1371/journal.pone.0244780

19. Ganczak M, Pasek O, Duda-Duma $Ł$, Świstara D, Korzeń M. Use of masks in public places in Poland during SARS-Cov-2 epidemic: a covert observational study. BBMC public Heal [Internet]. 2021;21(1):393.

Available from: http://www.ncbi.nlm.nih.gov/pubmed/33622279

20. Mohammed H, Oljira L, Roba KT, Yimer G, Fekadu A, Manyazewal T. Containment of COVID-19 in Ethiopia and implications for tuberculosis care and research. Infect Dis Poverty. 2020;9(1):1-8.

21. Sachs JD, Abdool Karim S, Aknin L, Allen J, Brosbøl K, Cuevas Barron G, et al. Priorities for the COVID- 
19 pandemic at the start of 2021: statement of the Lancet COVID-19 Commission. Lancet. 2021;6736(21):19-22.

22. Chane Teferi S. Knowledge, Attitude, and Practice During the COVID-19 Pandemic in Ethiopia: A Review. Int J Clin Exp Med Sci. 2020;6(5):104.

23. Kebede Y, Birhanu Z, Fufa D, Yitayih Y, Abafita J, Belay A, et al. Myths, beliefs, and perceptions about COVID-19 in Ethiopia: A need to address information gaps and enable combating efforts. PLoS One [Internet]. 2020;15(11 November):1-18. Available from: http://dx.doi.org/10.1371/journal.pone.0243024

24. Wondimu W, Girma B. Challenges and silver linings of COVID-19 in Ethiopia-short review. J Multidiscip Healthc. 2020;13:917-22.

25. Mclennan W. An Introduction to Sample Surveys: A User's Guide. Australi: AUSTRALIAN BUREAU OF STATISTICS; $1999.80 \mathrm{p}$.

26. Mchugh ML. Lessons in biostatistics The Chi-square test of independence. Lessons Biostat. 2013;23(2):143-9.

27. Peng CJ, Ingersoll GM. An Introduction to Logistic Regression Analysis and Reporting. J Educ Res. 2002;96(1):1-14.

28. Alsubaie S, Temsah MH, Al-eyadhy AA, Gosadi I, Gamal M. Original Article Middle East Respiratory Syndrome Coronavirus epidemic impact on healthcare workers ' risk perceptions, work and personal lives. J Infect Dev Ctries. 2019;13(10):920-6.

29. Giao H, Le An P, Thi Ngoc Han N, Van Khanh T, Kim Ngan V, Van Tam V. Knowledge and attitude toward COVID-19 among healthcare workers at District 2 Hospital, Ho Chi Minh City. Asian Pac J Trop Med. 2020;13(March):6-11.

30. Mya KS, Aye SM, Hlaing WA, Hlaing SS, Aung T, Lwin SMM, et al. Awareness, perceived risk and protective behaviours of Myanmar adults on COVID-19. 2020;7(5):1627-36.

31. BHAGAVATHUlA A, Aldhaleei WA, Rahmani JR, Mahabadi MA, Bandari DK. Novel Coronavirus (COVID-19) Knowledge and Perceptions: A Survey of Healthcare Workers (Preprint). JMIR Public Heal Surveill. 2020;6:1-9.

32. Kwok KO, Li KK, Chan HH, Yi YY, Tang A, Wei WI, et al. Community responses during the early phase of the COVID-19 epidemic in Hong Kong: risk perception, information exposure and preventive measures. medRxiv. 2020;2020.02.26.20028217.

33. Sciences A. Knowledge, Attitude and Practice among Healthcare Professionals regarding COVID-19: A 
cross-sectional survey from Pakistan. 2020;

34. Nooh HZ, Alshammary RH, Alenezy JM, Alrowaili NH, Alsharari AJ, Alenzi NM, et al. Public awareness of coronavirus in Al-Jouf region, Saudi Arabia. J Public Heal. 2020;13(2020 Feb):1-8. 
Figures

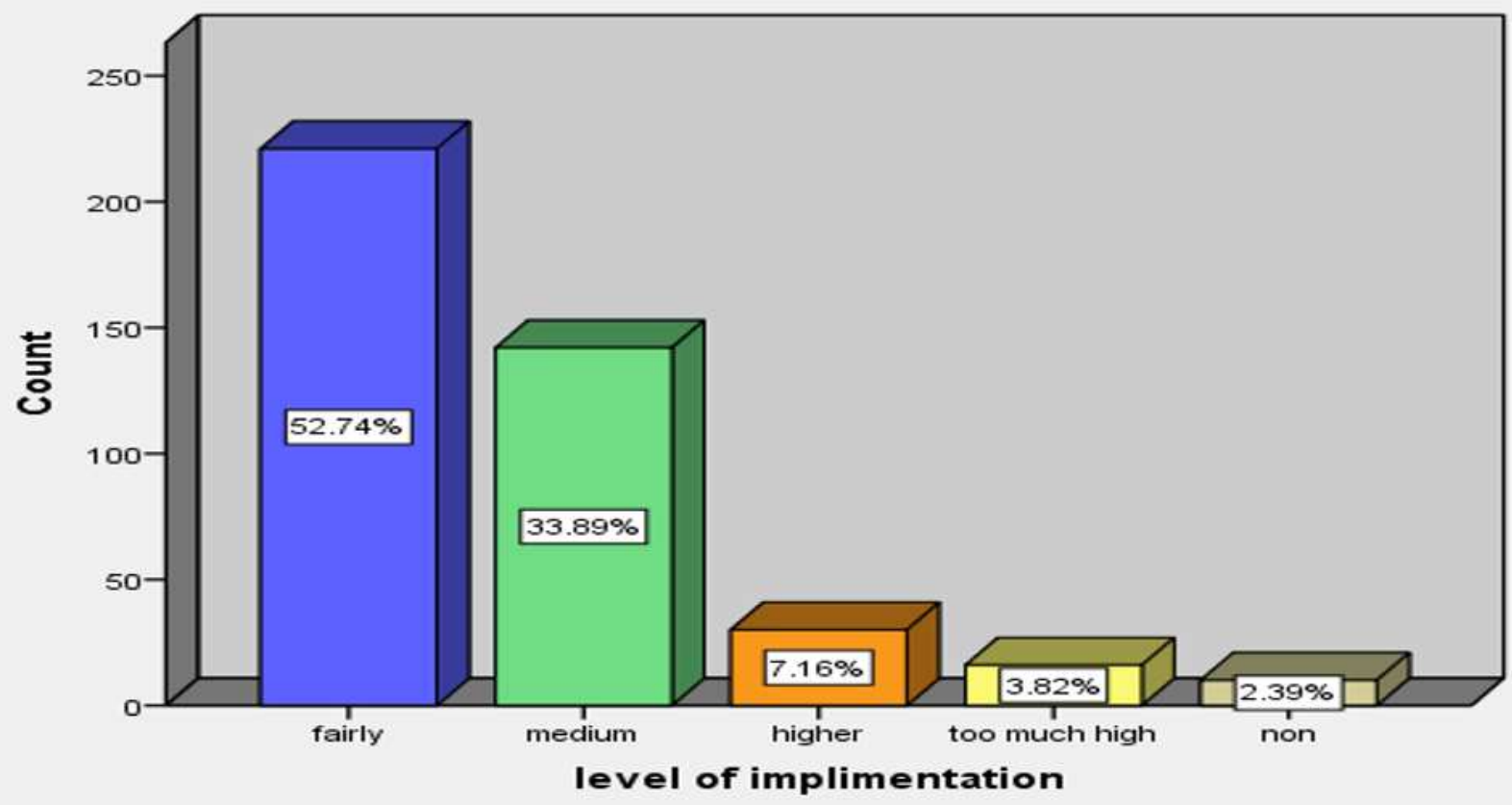

Figure 1

Level of implementation the government declaration regarding COVID-19 by individuals

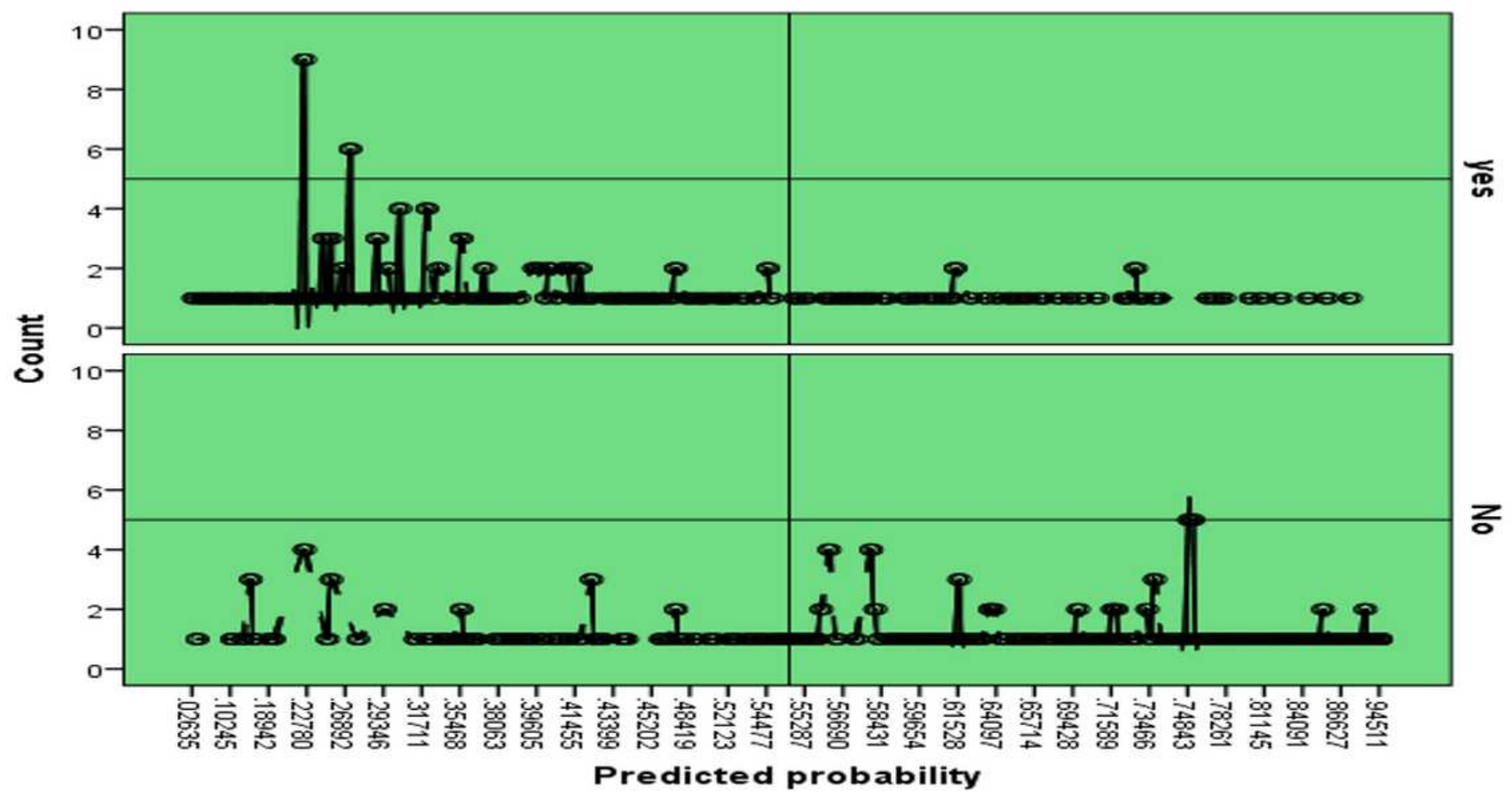


Predicted probability of individual towards COVID-19 